\title{
Thermal Conductivity of Epoxy Resin Filled with Particulate Aluminum Nitride Powder
}

\author{
Yuji NAGAI and Gao-Chao LAI \\ Research and Development Laboratory, Toyo Aluminium K. K., 4-1, Aioi-cho, Yao-shi, Osaka \\ 窒化アルミニウム添加エポキシ樹脂の熱伝導率 \\ 永井裕二。頼 高潮 \\ 東洋アルミニウム(株)研究開発本部研究所, 581 大阪府八尾市相生町 4-1
}

581

\begin{abstract}
The thermal conductivity of an $\mathrm{AIN}$ - and an alumina-particulate-filled epoxy resin was investigated as a function of their volume content ratios. AlN composite exhibited thermal conductivity of $7.15 \mathrm{~W} / \mathrm{m} \cdot \mathrm{K}$ at 68.5 vol\% filler content but that of alumina composite was lower than $2.68 \mathrm{~W} / \mathrm{m} \cdot \mathbb{K}$ even if the filler content was as much as 63.8 vol\%. The thermal conductivity of the composites is strongly dependint on that of the filler. In the AlN filler properties, the particle size of the filler used affected the thermal conductivity of composites, and composites with higher thermal conductivity could be obtained by using filler with large particle size. The thermal conductivity of composites is governed by the number of resin layers on the surface of an AlN particle. The composite thermal conductivities decreased with increasing the oxygen content of the filler. The thermal conductivity of an AlN particle depends on the oxygen content of the particle itself and the decrease of the composite thermal conductivity with the increase of the oxygen content of the filler is due to the increase of the aluminum oxide layer thickness produced on the surface of particles. In the thermal conductivity model, the measured thermal conductivity of AlN-ground-powder-filled composites disagreed with the ones calculated using Bruggeman's expression. However the measured values of aluminasphericall-powder-filled composites agreed with the calculated ones. It is considered that the results depended on the sphericity of the used powder. [Received July 2, 1996; Accepted November 12, 1996]
[
\end{abstract}

Keywords : Aluminum nitride, Epoxy resin, AlN filler, Alumina filler, Thermal conductivity, Thermal conductivity model, Composite

1. Introduction

The latest miniaturization of electronic devices and integrated circuits has caused an increase of power densities. The current trend in the field of microelectronic parts requires an epoxy resin with high thermal conductivity for encapsulating these heat-dissipating electronic components. ${ }^{1)-3)}$

Epoxy resin has a low thermal conductivity, about 0.15 to $0.25 \mathrm{~W} / \mathrm{m} \cdot \mathrm{K}, 4), 5)$ which can be increased by the addition of particulate inorganic filler materials with a high thermal conductivity. ${ }^{6)-8)}$ Since the thermal conductivity of the inorganic filler is much larger than that of the epoxy resin, the addition of fillers is an effective way of raising the thermal property of the epoxy resin. Silicon oxide (silica), in the fused or crystalline state, and aluminum oxide (alumina) particles have been used as the resin. $\left.{ }^{9)}-12\right)$ Recently, the addition of silicon nitride ( $\mathrm{SiN}$ ) or aluminum nitride (AIN) particles with higher thermal conductivity has been attempted.13)-15)

In this study, the thermal conductivities of the epoxy resins containing two kinds of particulate fillers were measured. Ground AlN and spherical alumina particles were employed as the filler. For AlN filler, in particular, the influence of the filling ratio and of the characteristics such as particle size and oxygen content on the composite thermal conductivities were studied.

\section{Experimental procedures}

To prepare test specimens, thermosetting epoxy resin powder modified with imido radical (Best Lex LS, Sumitomo Chemical Ind., Co., Ltd.) and particulate AIN material $\left(D_{50}=23.7 \mu \mathrm{m}\right.$, R335 Toyo Aluminium K. K.) made from direct nitridation of aluminum metal were mixed in a glass container. Properties of the particulate AlN material used in this experiment are shown in Table 1, and a scanning electron microscope (SEM) image of the AIN material is shown in Fig. 1. The mixed materials were put into circular cylinders with $12 \mathrm{~mm}$ diameter and $40 \mathrm{~mm}$ height made of

Table 1. Properties and Oxygen Content of AlN Powders

\begin{tabular}{ccc}
$\begin{array}{c}\text { Average Particle } \\
\text { Size } \\
(\mu \mathrm{m})\end{array}$ & $\begin{array}{c}\text { Specific Surface } \\
\text { Area } \\
\left(\mathrm{m}^{2} / \mathrm{g}\right)\end{array}$ & $\begin{array}{c}\text { Oxygen Content } \\
(\text { mass \%) }\end{array}$ \\
\hline 5.7 & 1.29 & 0.76 \\
10.3 & 0.47 & 0.45 \\
15.6 & 0.35 & 0.43 \\
19.0 & 0.25 & 0.36 \\
23.7 & 0.18 & 0.30 \\
26.1 & 0.14 & 0.30 \\
27.6 & 0.13 & 0.29 \\
\hline
\end{tabular}

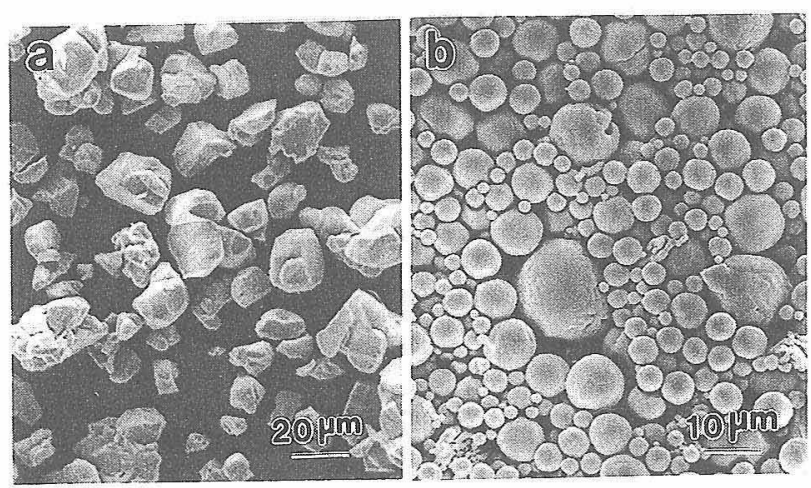

Fig. 1. Microstructures of (a) $\mathrm{AlN}$ and (b) $\mathrm{Al}_{2} \mathrm{O}_{3}$ powders. 


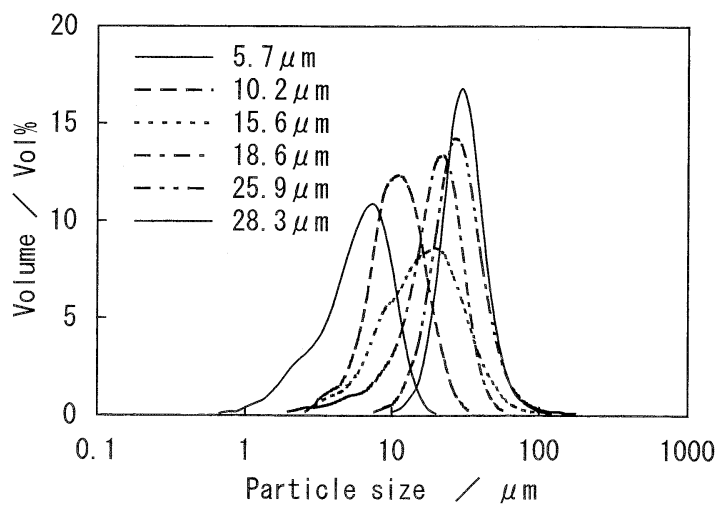

Fig. 2. Particle size distribution of AlN.

stainless steel and were pressed under $29 \mathrm{MPa}$. The green bodies were cured in an oven at $180^{\circ} \mathrm{C}$ for $30 \mathrm{~min}$. Specimens, with $10 \mathrm{~mm}$ diameter and $2 \mathrm{~mm}$ height, were obtained for the measurement of thermal conductivity.

For comparison, the same procedure was carried out to obtain test specimens filled with the particulate alumina material. Spherical alumina particles $\left(D_{50}=10 \mu \mathrm{m}\right.$ alumina beads CB, Showa Denko Co., Ltd.) were used. A SEM image of the alumina particles is also indicated in Fig. 1.

To investigate the effect of the particle size of AlN filler on the thermal conductivity of epoxy resin-AlN composites, various powders with different particle sizes were prepared by grinding a coarse AlN powder and adjusting the average particle size of ground powders by classification. The properties of the powders are also shown in Table 1 and their particle size distributions are shown in Fig. 2. Furthermore, in order to study the influence of oxygen content in AlN powder on the composite thermal conductivities, that of AlN powder with average particle size of $20.4 \mu \mathrm{m}$ was adjusted by controlling heat treatment time at $450^{\circ} \mathrm{C}$.

Densities and thermal conductivities of specimens were measured by the water displacement and laser flash methods (TC-3000H-NC, Sinku-Riko, Inc.), respectively. Before measuring thermal conductivity, the surfaces of specimens were covered with carbon by spray coating.

\section{Results and discussion}

\subsection{Thermal conductivities of composites}

The addition of AlN and alumina fillers to the epoxy resin resulted in a steady increase in the thermal conductivity of the composites, as shown in Fig. 3. The thermal conductivities of both composites rose with increasing filler content. AlN composite exhibited thermal conductivity of $7.15 \mathrm{~W} /$ $\mathrm{m} \cdot \mathrm{K}$ at $68.5 \mathrm{vol} \%$ filler content. However alumina composite had lower thermal conductivity of $2.68 \mathrm{~W} / \mathrm{m} \cdot \mathrm{K}$ even if the filler content was as high as $63.8 \mathrm{vol} \%$. This result reveals that an epoxy composite with high thermal conductivity can be obtained by using AlN filler. There is a large difference between the thermal condutivities of AlN- and alumina-filler-added epoxy resin composites. It is obvious that the thermal conductivity of epoxy resin composites is strongly dependent on the type of filler.

\subsection{Effect of particle size of AIN powder}

Relationship between the thermal conductivity of composite and the average particle size of filled AlN powders is shown in Fig. 4. The filler content was fixed at $60 \mathrm{vol} \%$. In this experiment (Fig. 4), the relative density of specimens is as follows: $95.5 \%$ for $D_{50}=5.7 \mu \mathrm{m}, 97.7 \%$ for $D_{50}=10.3$ $\mu \mathrm{m}, 98.2 \%$ for $D_{50}=15.6 \mu \mathrm{m}, 98.7 \%$ for $D_{50}=19 \mu \mathrm{m}$, $98.3 \%$ for $D_{50}=26.1 \mu \mathrm{m}$, and $97.5 \%$ for $D_{50}=27.6 \mu \mathrm{m}$. The specimen has a slightly lower density of small powder, 5.7

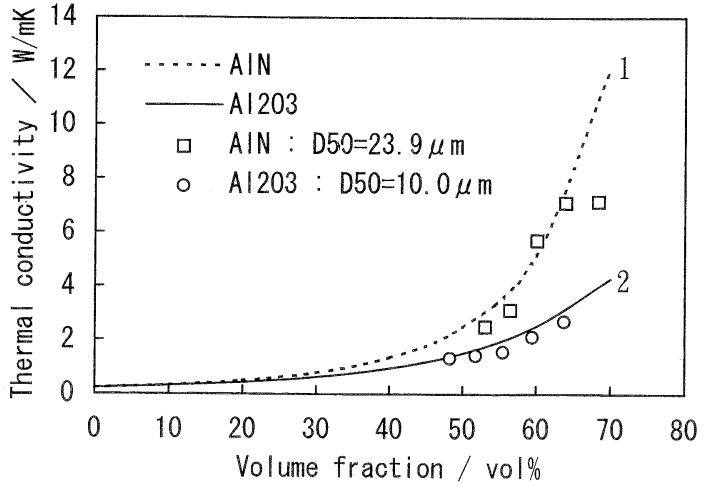

Fig. 3. Variation in thermal conductivity as a function of filler content.

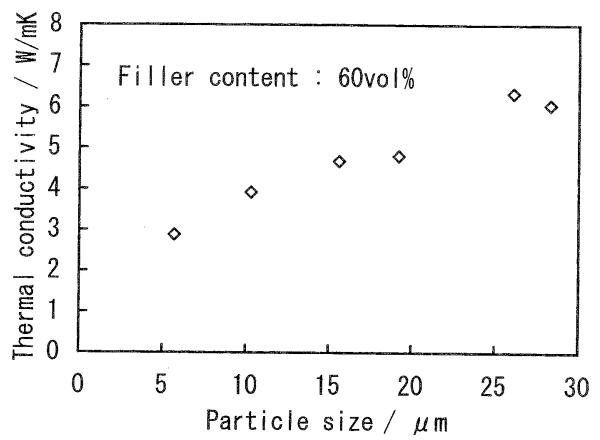

Fig. 4. Relationship between thermal conductivity of composites and size of AlN filler particles.

$\mu \mathrm{m}$, in comparison to specimens with other fillers but it is recognized that there is no obvious difference among these specimens and no influence on the thermal conductivity of the composite density. The thermal conductivities of composites rose with increasing particle size. The use of large powder particles is an effective way of increasing the thermal conductivity of composites.

Assuming that the AlN fillers used in this study are spherical and dispersed uniformly in the epoxy resin matrix, their volume fraction can be given as,

$$
V=n_{1} 4 / 3 \pi r_{1}^{3}=n_{2} 4 / 3 \pi r_{2}{ }^{3}=n_{3} 4 / 3 \pi r_{3}^{3}=n_{\mathrm{i}} 4 / 3 \pi r_{\mathrm{i}}{ }^{3}
$$

where $V$ : volume fraction AlN filler,

$n:$ number of AlN filler particles,

$\pi$ : ratio of particle circumference to its diameter,

$r$ : radius of AlN filler particle.

From Eq. (1), the relation between $r$ and $n$ can be derived as.

$$
\left(\frac{r_{1}}{r_{2}}\right)^{3}=\frac{n_{2}}{n_{1}}
$$

Since $V$ is fixed in the result shown in Fig. 3, on the basis of Eq. (2), it is understood that when $r$ of filler particles is increased, $n$ decreases rapidly. The number of filler particles in the matrix strongly depends on the particle size. Meanwhile, a particle in the epoxy resin matrix inevitably has a resin layer on its surface, the thickness of which is constant regardless of the particle size because the volume fraction of filler is fixed and filler is dispersed uniformly in the matrix. The number of the resin layers is numerous in the matrix filled with small filler particles in comparison to the matrix filled with large particles. In the AlN-filled composites, added heat is carried from one side to the opposite side of the composite through a resin layer and an AlN particle in turn and at this time, as the thermal conductivity of 


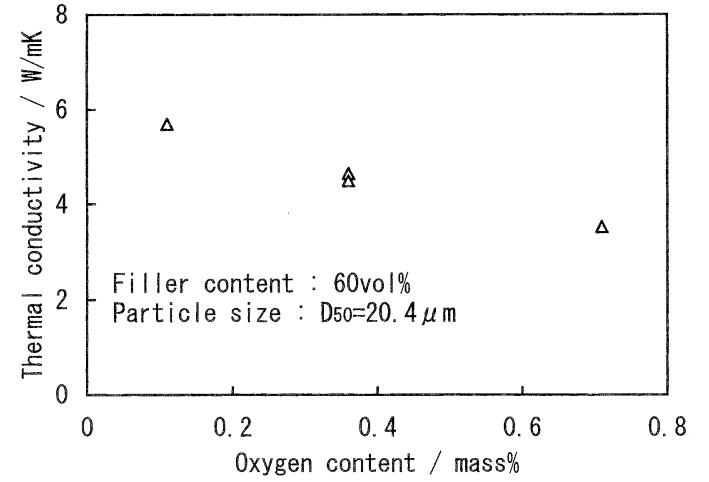

Fig. 5. Thermal conductivity of composites as a function of the oxygen content in the AIN filler.

epoxy resin is lower, that of the composite decreases gradually as heat is carried through the resin layer. Therefore the thermal conductivity of epoxy composites filled with small AlN filler particles becomes lower than that of largeparticle-filled composites.

\subsection{Effect of oxygen content of powder}

The variation in thermal conductivity of composites as a function of total oxygen content of AlN powders is shown in Fig. 5. The thermal conductivity of composites decreased with increasing total oxygen content of AlN powder. It can be understood that the thermal conductivity of AlN-filled composites is influenced by the oxygen content of powder. To increase the thermal conductivity of composites, it is better to use AlN powder with lower oxygen content.

There are many reports concerning the relationship between thermal conductivity and the oxygen content of AIN powder and sintered bodies. ${ }^{16)}{ }^{-18)}$ All reports mention that the oxygen content of powder and sintered bodies influences the thermal conductivity of sintered bodies. Higher oxygen content causes lower thermal conductivity. From the discussions, it is understood that the thermal conductivity of a particle of AlN ceramics is basically governed by the oxygen content in the particle itself. In this study, the increase of total oxygen content of the AlN powders used is caused by oxidation at the time of heat treatment and an oxidized substance, aluminum oxide compounds, is produced on the surface of a particle in the form of a thin layer. Then the increase of total oxygen content of the filler can be understood to correspond to the thickness of the aluminum oxide layer. Since the thermal conductivity of aluminum oxide compounds is lower than that of AlN, that of an AlN particle having a high total oxygen content (thick aluminum oxide layer), is naturally decreased. Therefore, an addition of high oxygen content filler to the epoxy resin does not greatly increase the thermal conductivity of the composites.

\subsection{Thermal conductivity models}

Many reports concerning the thermal conductivity of resin composites filled with various inorganic materials as filler have appeared and its relations to the volume fraction of filler have been theoretically discussed.7),19)-27) Among them, Bruggeman presented the following expression for the relationship between the thermal conductivity of composite and the volume fraction of filler. ${ }^{19)}$

$$
\begin{aligned}
1-v= & \frac{\lambda_{\mathrm{e}}-\lambda_{\mathrm{d}}}{\lambda_{\mathrm{c}}-\lambda_{\mathrm{d}}}\left(\frac{\lambda_{\mathrm{c}}}{\lambda_{\mathrm{e}}}\right)^{1 / 3} \\
& v: \text { volume fraction } \\
& \lambda_{\mathrm{e}}: \text { thermal conductivity of composite } \\
& \lambda_{\mathrm{d}}: \text { thermal conductivity of filler } \\
& \lambda_{\mathrm{c}}: \text { thermal conductivity of matrix }
\end{aligned}
$$

On the other hand, Kanari ${ }^{20)}$ revised Bruggeman's equation, expanding the theoretical expression derived by Hamilton and others: ${ }^{24)}$

$$
1-v=\frac{\lambda_{\mathrm{e}}-\lambda_{\mathrm{d}}}{\lambda_{\mathrm{c}}-\lambda_{\mathrm{d}}}\left(\frac{\lambda_{\mathrm{c}}}{\lambda_{\mathrm{e}}}\right)^{1 /(1+x)}
$$

where $v, \lambda_{\mathrm{e}}, \lambda_{\mathrm{d}}$ and $\lambda_{\mathrm{c}}$ are the same as in Eq. (3), and $x$ is the constant determined by sphericity of the filler and $\lambda_{\mathrm{d}} / \lambda_{\mathrm{c}}{ }^{22)}$ or by only the sphericity of the filler. ${ }^{24)}$ When the value of $180 \mathrm{~W} / \mathrm{m} \cdot \mathrm{K}^{28}$ ) is substituted as the thermal conductivity of the AlN filler into Eq. (3), thermal conductivity of the composites with various filler volume fractions can be calculated. Using the same value of thermal conductivity and by changing the value of $x$ in Eq. (4), thermal conductivity of the composites also can be calculated.

The same calculation was carried out for the alumina composites using the value of $20 \mathrm{~W} / \mathrm{m} \cdot \mathrm{K}^{29)}$ as the thermal conductivity of the alumina filler for Bruggeman's Eq. (3) and Kanari's Eq. (4). As a result of calculation for AIN and alumina composites, the values of thermal conductivities calculated using Kanari's equation are found to be higher than those calculated using Bruggeman's equation. For A1N composites the measured data do not agree with the values calculated using Bruggeman's equation, but generally agree with the values obtained using Kanari's equation with the numerical value of 2.5 substituted for $x$. The results are shown in Fig. 3 (dotted line 1). However, in alumina composites, the measured data agree with the values calculated using Bruggeman's equation for every plot; the results are also shown in Fig. 3 (solid line 2). It is estimated that this phenomenon is related to the sphericity of the filler used, since Bruggeman's equation can only be applied to composites with spherical fillers.7),20) Therefore, it is necessary to revise Bruggeman's equation for nonspherical AlN fillers.

\section{Conclusion}

The thermal conductivity of epoxy resin composites filled with particulate AlN and alumina fillers increased with increasing filler content. An AIN composite exhibited the thermal conductivity of $7.15 \mathrm{~W} / \mathrm{m} \cdot \mathrm{K}$ with the filler content of 68.5 vol $\%$, but an alumina-filled composite had lower thermal conductivity of $2.68 \mathrm{~W} / \mathrm{m} \cdot \mathrm{K}$ at $63.8 \mathrm{vol} \%$ filler content. The thermal conductivity of the composites is strongly dependent on that of filler.

In the AlN-filled epoxy composites, the particle size of the filler used influenced the thermal conductivity, and composites with higher thermal conductivity could be obtained by using larger filler particles. On the basis of the calculation results on the relation between the number of particles and particle size, the total number of epoxy resin layers on the surfaces of large particles in the composite is greatly decreased in comparison with that of small particles. Therefore, the use of large filler particles increases the thermal conductivity of the resin matrix more than does the use of small filler particles.

The total oxygen content of AlN filler affected the thermal conductivity of epoxy resin composites, which decreased with increasing total oxygen content of the filler. The thermal conductivity of an AlN particle depends on the oxygen content of the particle itself. An increase of oxygen content due to oxidation between AIN and oxygen produces aluminium oxide compounds in the form of a thin layer on the surface of a particle and can be understood to be the thickness of the layer. The presence of this layer reduces the thermal conductivity of the particle itself.

In thermal conductivity models, the measured thermal conductivities of AlN composites filled with ground powder did not agree with the ones calculated using Bruggeman's equation, but agreed with those calculated using Kanari's 
equation (revised Bruggeman's equation). Conversely, the measured thermal conductivities of alumina composites filled with spherical powder agreed with the ones calculated using Bruggeman's equation. It is estimated that this phenomenon is related to the sphericity of the filler particle.

\section{References}

1) K. Nakamura, Nikkei Microdevices, No. 9, 91-99 (1989).

2) A. Fukuda, Nikkei Electronics, No. 518, 123-36 (1991).

3) K. Yoshimoto, JETI, 42, 348-51 (1994).

4) H. Lee and K. Neville, "Handbook of Epoxy Resins," McGraw Hill (1982) pp. 14-24.

5) C. I. Nicholls and H. M. Rosenberg, J. Phys. D: Appl. Phys., 17, 1247-58 (1974).

6) D. W. Sundstrom and Y. D. Lee, J. Polymer Sci., 50, 441-50 (1961).

7) K. Kanari, High Polymers Japan, 26, 557-61 (1977).

8) K. Hani, "Kinousei Filler no Saisin Gijutu," CMC (1990) pp. 136-43.

9) B. Reich, Solid State Tech., 21, 82-86 (1978).

10) M. Ogata, T. Kawata and N. Kinjo, J. J. Polymer Sci. and Tech., 44, 193-99 (1989).

11) K. Takahashi, Kogyo Zairyo, 42, 112-16 (1994).

12) K. Matsumoto, Shin Sozai, No. 5, 22-25 (1996).

13) P. Bujard and J. P. Ansermet, Proceeding of the 5th IEEE SEM-THERM Symp. (1989) pp. 126-30.
14) H. Ikeya, Polymer Preprints. Japan, 39, 1340 (1990).

15) K. Matsumoto and K. Uchida, Proc. of Thermosetting Plas. Sym. Japan (1994) pp. 29-32.

16) G. A. Slack, J. Phys. Chem. Solids, 34, 321-35 (1973).

17) H. Buhr, G. Muller, H. Wiggers, F. Aladinger, P. Foley and A. Roosen, J. Am. Ceram. Soc., 74, 718-23 (1991).

18) G. E. Potter, A. K. Knudsen and J. C. Tou, J. Am. Ceram. Soc., 75, 3215-23 (1992).

19) D. A. G. Bruggeman, Ann. Phys., 24, 636-64 (1935).

20) K. Kanari, Dai 14 Kai Nippon Dennetu Sinpojiumu Ronbunshu (1977) pp. 208-10.

21) J. C. Maxwell, "A Treatise on Electicity and Magnetism," Vol. 1, Oxford Press (1904) pp. 418-64.

22) H. Fricke, Phys. Rev., 24, 575-87 (1924).

23) R. E. Meredith and C. W. Tobios, J. Electrochemical Soc., 108, 286-90 (1961).

24) R. L. Hamilton and O. K. Crosser, Ind. Eng. Chem. Fundam., 1, 187-91 (1962).

25) S. C. Cheng and R. I. Vochon, Int. J. Heat Mass Transfer, 12, 249-64 (1969).

26) D. W. Sandstrom and Y. Lee, J. Appl. Polymer Sci., 16, 3159 67 (1972).

27) L. E. Nielsen, Ind. Chem. Fundam., 13, 17-20 (1974).

28) Sinsozai Manual Hensyuiinkai, "Sinsozai Manual", Tekunopuraza (1991) p. 63.

29) Sinsozai Manual Hensyuiinkai, “Sinsozai Manual”, Tekunopuraza (1991) p. 48. 